OPEN ACCESS

Edited by:

Luigi Cattivelli,

Research Centre for Genomics and Bioinformatics, Counci

for Agricultural and Economics

Research, Italy

Reviewed by:

Urmil Bansal,

University of Sydney, Australia

Pablo Daniel Olivera,

University of Minnesota Twin Cities,

United States

*Correspondence:

Chaojie Xie

xiecj127@126.com

Specialty section:

This article was submitted to

Plant Breeding,

a section of the journal

Frontiers in Plant Science

Received: 26 November 2019 Accepted: 30 March 2020

Published: 06 May 2020

Citation:

Qiu L, Wang H, Li Y, Wang W, Liu Y, Mu J, Geng M, Guo W, Hu Z, Ma J, Sun $Q$ and Xie C (2020) Fine Mapping of the Wheat Leaf Rust

Resistance Gene LrLC10 (Lr13) and Validation of Its Co-segregation

Markers. Front. Plant Sci. 11:470.

doi: 10.3389/fpls.2020.00470

\section{Fine Mapping of the Wheat Leaf Rust Resistance Gene LrLC10 (Lr13) and Validation of Its Co-segregation Markers}

\author{
Lina Qiu', Huifang Wang ${ }^{1}$, Yinghui Li ${ }^{1,2}$, Weidong Wang ${ }^{1}$, Yujia Liu' ${ }^{1}$, Junyi Mu', \\ Miaomiao Geng ${ }^{1,3}$, Weilong Guo ${ }^{1}$, Zhaorong Hu${ }^{1}$, Jun Ma', Qixin Sun ${ }^{1}$ and Chaojie Xie ${ }^{1 *}$ \\ 1 State Key Laboratory for Agrobiotechnology, Key Laboratory of Crop Heterosis and Utilization (MOE), Key Laboratory \\ of Crop Genetic Improvement, China Agricultural University, Beijing, China, ${ }^{2}$ Institute of Evolution, University of Haifa, Haifa, \\ Israel, ${ }^{3}$ College of Agronomy Hebei Agricultural University, Hebei Agricultural University, Baoding, China
}

Wheat leaf rust, caused by the fungus Puccinia triticina Eriks. (Pt), is a destructive disease found throughout common wheat production areas worldwide. At its adult stage, wheat cultivar Liaochun10 is resistant to leaf rust and the gene for that resistance has been mapped on chromosome 2BS. It was designated LrLC10 and is the same gene as cataloged gene Lr13 by pedigree analysis and allelism test. We fine-mapped it using recessive class analysis (RCA) of the homozygous susceptible $F_{2}$ plants derived from crosses using Liaochun10 as the resistant, male parent. Taking advantage of the re-sequencing data of Liaochun10 and its counterpart susceptible parent, we converted nucleotide polymorphisms in the LrLC10 interval between the resistant and susceptible parents into molecular markers to saturate the LrLC10 genetic linkage map. Four indel markers were added in the $1.65 \mathrm{cM}$ map of LrLC10 flanked by markers CAUT163 and Lseq22. Thirty-two recombinants were identified by those two markers from the $984 F_{2}$ homozygous susceptible plants and were further genotyped with additional ten markers. LrLC10 was finally placed in a $314.3 \mathrm{~kb}$ region on the Chinese Spring reference sequence (RefSeq v1.0) that contains three high confidence genes: TraesCS2B01G182800, TraesCS2B01G182900, and TraesCS2B01G183000. Sequence analysis showed several variations in TraesCS2B01G182800 and TraesCS2B01G183000 between resistant and susceptible parents. One KASP marker and an indel marker were designed based on the differences in those two genes, respectively, and were validated to be diagnostic co-segregating markers for $L r L C 10$. Our results both improve markerassisted selection and help with the map-based cloning of LrLC10.

Keywords: wheat, LrLC10 (Lr13), leaf rust resistance, fine mapping, marker-assisted selection (MAS)

\section{INTRODUCTION}

Globally, common wheat (Triticum aestivum) is one of the most commonly cultivated crops, comprising $20 \%$ of human caloric intake and $15 \%$ of cultivated area in the world (FAOSTAT, 2015; WAP, 2017). Wheat leaf rust, caused by Puccinia triticina Eriks. (Pt) is one of the most damaging 
diseases of wheat, especially in coastal regions or areas with high temperatures and humidity during the wheat maturing seasons (Kolmer et al., 2018). In China, past widespread wheat leaf rust epidemics have caused severe yield losses (Dong, 2001; Zhou et al., 2013). In the future, due to impending climate change, leaf rust is expected to damage wheat production even more (Jiang et al., 2018). Utilization of wheat resistant cultivars considered a most effective, economical and environmentallyfriendly strategy for controlling this disease (Bariana et al., 2007; Singh et al., 2013).

Currently, about 80 leaf rust resistant genes have been reported and formally named in common wheat or its relatives (McIntosh et al., 2017; Qureshi et al., 2018), and by using different types of molecular markers, most of these genes have been mapped on the wheat chromosomes ${ }^{1}$. Development of robust molecular markers linked to resistance genes is essential in wheat disease resistance breeding, especially for resistance gene pyramiding. Nevertheless, among these designated leaf rust resistance genes, only a few have tightly linked molecular markers for marker-assisted selection ${ }^{2}$.

Because of limited wheat genomic sequence data, developing molecular markers for wheat genes has been difficult. But now, by combining the $T$. aestivum 'Chinese Spring' (CS) IWGSC RefSeq v1.0 genome ${ }^{3}$ with annotations of high-quality gene models, these difficulties have been reduced, especially for gene location and markers development (Clavijo et al., 2017). Discovery of the highly abundant, locus-specific wheat nucleotide variations that can be used to identify the relevant genes are now within grasp because of affordable next-generation sequencing (Varshney et al., 2014; Xu et al., 2017). Compared with other kinds of markers, kompetitive allele-specific PCR (KASP) assays accelerate the conversion of DNA variations into available gene-linked markers. Taking advantage of such whole genomic sequences, Wu et al. (2018b) mapped wheat yellow rust resistance gene $Y r 26$ on a $0.003-c M$ interval on chromosome $1 \mathrm{~B}$ near the centromere, Narang et al. (2019) defined wheat leaf rust resistance gene $\operatorname{LrP}$ and yellow rust resistance gene $\mathrm{YrP}$ on a 15.71 Mb region on 5DS in the CS RefSeq v1.0 genome assembly, and $\mathrm{Wu}$ et al. (2019) localized the Pm52 locus within a $5.6 \mathrm{Mb}$ interval on the long arm of chromosome $2 \mathrm{~B}(2 \mathrm{BL})$.

Bulked segregant analysis (BSA) can rapidly identify markers linked to target genes (Michelmore et al., 1991), and it has been improved by bulking homozygous recessive plants and using recessive class analysis (RCA) to map specific genes (Zhang et al., 1994). RCA is highly efficient, with a lower probability of misclassification and more reliability than using a random $\mathrm{F}_{2}$ population. Furthermore, this approach avoids creating $\mathrm{F}_{2: 3}$ families and screening the entire $F_{2}$ population, thus saving time in fine mapping and map-based cloning. RCA has been proven to map genes efficiently and reliably (Zhang et al., 1994; Yao et al., 1997; Mei et al., 1999; Chen et al., 2006; Kiswara et al., 2014). In wheat, rapid gene mapping using RCA has been used to map a sterile female gene (Dou et al., 2009) and a

\footnotetext{
${ }^{1}$ https://shigen.nig.ac.jp/wheat/komugi/

${ }^{2}$ https://maswheat.ucdavis.edu/protocols/index.htm

${ }^{3}$ https://www.wheatgenome.org/
}

stripe rust resistance gene, $Y r L M 168 a$ (Feng et al., 2015), and to successfully map and clone the powdery mildew resistance gene Pm60 (Zou et al., 2018).

In wheat, Lr13, first identified in the Canadian cultivar "Manitou" in 1966, is an important adult-plant leaf rust resistance gene (McIntosh et al., 1995) that is widely found in wheat cultivars (e.g., 'Frontana,' 'Frondoso,' and 'Fronteria') and used in many breeding programs throughout the world (Roelfs, 1988; Pathan and Park, 2006). In China, Lr13 is one of the main resistance genes and confers effective resistance to leaf rust (Singh et al., 1999; Yuan et al., 2007; Yuan and Chen, 2011; Ren et al., 2015; Zhang et al., 2019). Previous studies indicated that $\operatorname{Lr} 13$ was located on chromosome 2BS (McIntosh et al., 1995), and Bansal et al. (2008) reported $\operatorname{Lr} 13$ was delimited to a $13.8 \mathrm{cM}$ interval flanked by markers $X k s m 58$ and Xstm773b. Recently, using a segregating population of $\operatorname{Lr} 13$ near-isogenic lines with simple sequence repeat and KASP markers, Zhang et al. (2016) mapped Lr13 to a small interval of $10.7 \mathrm{cM}$, and the closest marker was kwh37 (4.9 cM). A morphological marker, hybrid necrosis gene Ne2m, was found linked to Lr13 by Singh and Gupta (1991), but it cannot be used to accurately detect $\operatorname{Lr} 13$ (Anand et al., 1991). Therefore, a co-segregated and diagnostic marker for $\operatorname{Lr} 13$ in molecular breeding is yet unavailable.

In this study, we confirmed that the leaf rust resistance gene $\operatorname{LrLC10}$ in Liaochun10 is $\operatorname{Lr} 13$ by pedigree analysis, and finely mapped it to a close interval with recessive class analysis (RCA) through the markers developed according to the resequencing data of the parental lines. We also developed molecular markers that were closely linked to LrLC10 and that can be used to facilitate marker-assisted selection of LrLC10 in wheat resistance breeding.

\section{MATERIALS AND METHODS}

\section{Plant Materials}

The spring wheat cultivar Liaochun10, is highly resistant to leaf rust, was crossed with two susceptible wheat lines Han 87-1 (87-1) and 7D49 (a wild emmer wheat introgression line created by the crossing IW123/Zheng98//87-1*2), to construct two $\mathrm{F}_{2}$ segregating populations of 3,908 plants. Wild emmer wheat IW123 was donated by T. Fahima and E. Nevo, University of Haifa, Israel and Lr13-carrier line RL4031 was provided by Zaifeng Li, College of Plant Protection, Heibei Agricultural University, China. The 1,395 $\mathrm{F}_{2}$ plants derived from the Liaochun10 $\times$ RL4031 cross were used to test allelism. A total of 35 cultivars with known presence/absence of $\operatorname{Lr} 13$ were chosen to validate the co-segregating markers (Table 1). A panel of 524 Chinese wheat accessions/landraces was used to test the Lr13 frequencies (Supplementary Table S1). Through all the experiments, a susceptible, common wheat line, Xuezao, was used to check for successful inoculation.

\section{Field Evaluation of Leaf Rust Symptoms at the Adult Stage}

Wheat leaf rust isolate PHT (provided by the Institute of Plant Protection, Chinese Academy of Agricultural Sciences, Beijing, 
TABLE 1 | Phenotype of 35 common wheat cultivars and genotyped with Lseq302 and Lseq102.

\begin{tabular}{|c|c|c|c|c|}
\hline Accession & Phenotype & Lseq302 & Lseq102 & $\begin{array}{l}\text { Progressive } \\
\text { necrosis }\end{array}$ \\
\hline Zhoumai30 & Resistant & A & $A$ & $\mathrm{~N}$ \\
\hline Apache & Resistant & A & $A$ & Y \\
\hline Maris Dove & Resistant & A & A & Y \\
\hline Gaoyou2018 & Resistant & $A$ & $A$ & Y \\
\hline Gaoyou9828 & Resistant & A & $A$ & Y \\
\hline Gaoyou5766 & Resistant & A & $A$ & Y \\
\hline Kenong2009 & Resistant & A & A & $\mathrm{N}$ \\
\hline Shannong06-278 & Resistant & A & $A$ & $\mathrm{~N}$ \\
\hline Cunmai11 & Resistant & A & A & $\mathrm{N}$ \\
\hline Yannong999 & Resistant & A & A & $\mathrm{N}$ \\
\hline Yunmai53 & Resistant & A & A & Y \\
\hline 16Y2N137 & Resistant & $A$ & A & Y \\
\hline 16Y2N132 & Resistant & A & $A$ & Y \\
\hline $16 Y 2 N 1688$ & Resistant & A & $A$ & Y \\
\hline Zhoumai36 & Resistant & A & A & $\mathrm{N}$ \\
\hline 90214 & Resistant & A & A & Y \\
\hline Zhouyuan9369 & Resistant & A & A & $\mathrm{N}$ \\
\hline Bainong419 & Resistant & A & A & $\mathrm{N}$ \\
\hline Nongda211 & Resistant & A & $A$ & Y \\
\hline Nongda212 & Resistant & A & A & Y \\
\hline Altgold & Resistant & A & $A$ & Y \\
\hline Liangxing66 & Resistant & A & A & $\mathrm{N}$ \\
\hline Cl12633 & Resistant & A & $A$ & Y \\
\hline Nongda1108 & Resistant & B & B & $\mathrm{N}$ \\
\hline Zhongmai66 & Resistant & B & B & $\mathrm{N}$ \\
\hline Nongda3432 & Susceptible & B & B & $\mathrm{N}$ \\
\hline Liangxing99 & Susceptible & B & B & $\mathrm{N}$ \\
\hline Xinmai26 & Susceptible & B & $\mathrm{B}$ & $\mathrm{N}$ \\
\hline Shi4185 & Susceptible & B & B & $\mathrm{N}$ \\
\hline Nongda4503 & Susceptible & B & B & $\mathrm{N}$ \\
\hline Jimai229 & Susceptible & B & B & $\mathrm{N}$ \\
\hline Xuezao & Susceptible & B & B & $\mathrm{N}$ \\
\hline Gao5 & Susceptible & B & B & $\mathrm{N}$ \\
\hline CA1062 & Susceptible & B & B & $\mathrm{N}$ \\
\hline Nongda3753 & Susceptible & $B$ & $B$ & $\mathrm{~N}$ \\
\hline
\end{tabular}

$Y$, indicates progressive necrosis; $N$, indicates the cross was not tested; $A$, indicates the band is identical with resistant parent; $B$, indicates the band is identical with susceptible parent.

China) was used as the inoculum. PHT isolate was avirulent on Liaochun 10 and RL4031.

The populations were sown at the experiment farm of China Agriculture University, Beijing, China. At the late tillering stage (Feekes stage 5) at least one tiller of each plant was inoculated by injecting urediniospore suspended in $0.1 \%$ Tween 20 into the leaf bundle with a $10 \mathrm{~mL}$ syringe. The urediniospore was propagated in the greenhouse on the susceptible control, Xuezao.

The infection type of the flag leaf and the top second leaf of each individual was evaluated about 1-2 month postinoculation when the susceptible control was fully infected, based on an infection type scale of $0-4$, where 0 indicated no visible symptoms, 0 ; indicated hypersensitive flecks, and 1-4, indicated small uredinia with necrosis, small- to medium-sized uredinia with green islands and surrounded by necrosis or chlorosis, medium- to large-sized uredinia with chlorosis, and large uredinia without chlorosis, respectively. Values 0-2 were categorized as resistant and 3-4 were classified as susceptible (Roelfs et al., 1992). A second assessment was conducted for each plant 4 days after the first examination.

\section{Allelism Tests}

We used an $\mathrm{F}_{2}$ population derived from Liaochun $10 \times$ RL4031 to determine the allelic relationships between genes $\operatorname{Lr} 13$ and LrLC10. The responses of each $\mathrm{F}_{2}$ plant to $P t$ race PHT was determined by the rust response method described above.

\section{Development of Molecular Markers}

The sequences of all the markers anchored in the $\operatorname{LrLC10}$ (Lr13) genetic linkage map were used as queries to search against the Chinese Spring reference genome sequence (RefSeq v1.0) to define the genome interval of the resistance gene on chromosome arm 2BS. Near the LrLC10 locus, singlenucleotide polymorphisms (SNPs) or insertion/deletion (indel) polymorphisms were found based on re-sequencing result of the two parents (the concrete method refer to Chai et al., 2018) and the $300 \mathrm{bp}$ flanking sequence of those indel sites which were $\geq 5 \mathrm{bp}$ that were obtained from the Chinese Spring reference genome sequence ${ }^{4}$, Primer3 (v.0.4.0) $)^{5}$ was used to design the indel markers. The SNPs or indels $(<5 \mathrm{bp})$ were converted into kompetitive allele-specific PCR (KASP) markers, which were designed using PolyMarker ${ }^{6}$. The markers used in this study were listed in Table 2.

\section{Marker Genotyping Assays}

PCR amplification was conducted in a $10 \mu \mathrm{L}$ reaction volume consisting of $5 \mu \mathrm{L} 2 \times$ Tag PCR StarMix with loading dye, 50$100 \mathrm{ng} / \mu \mathrm{L}$ DNA $1.5 \mu \mathrm{L}, 1.5 \mu \mathrm{L}$ primer (mixture of forward and reverse primer, $2 \mu \mathrm{M}$ ), and $2 \mu \mathrm{L} \mathrm{H}_{2} \mathrm{O}$. PCR proceeded with initial denaturation at $94^{\circ} \mathrm{C}$ for $5 \mathrm{~min}$, then 35 cycles at $94^{\circ} \mathrm{C}$ for $30 \mathrm{~s}, 30 \mathrm{~s}$ at $50-60^{\circ} \mathrm{C}$ for primer annealing (depending on the specific primers), $72^{\circ} \mathrm{C}$ for $30 \mathrm{~s}$ of extension; and the final extension at $72^{\circ} \mathrm{C}$ for $5 \mathrm{~min}$. The PCR product was separated in either $8 \%$ or $10 \%$ non-denaturing polyacrylamide gels (acrylamide:bisacrylamide $=39: 1$ ) that were silver stained and photographed. KASP assays were performed following the protocol described in Wu et al. (2018a).

\section{Construction of the Genetic Linkage Map}

We performed chi-square analysis of the leaf rust test data from the segregating $\mathrm{F}_{2}$ populations to confirm the goodnessof-fit of the observed ratios to theoretical expectations. The recombination frequencies of the resistance gene and the markers were calculated according to Chen et al. (2006). Using the Kosambi mapping function, we converted the recombination

\footnotetext{
${ }^{4}$ https://www.wheatgenome.org/

${ }^{5}$ http://bioinfo.ut.ee/primer3-0.4.0

${ }^{6}$ http://www.polymarker.info/
} 
TABLE 2 | Markers used in this study.

\begin{tabular}{|c|c|c|c|c|}
\hline Marker & $\begin{array}{l}\text { Marker } \\
\text { type }\end{array}$ & $\begin{array}{l}\text { Forward } \\
\text { primer }\end{array}$ & $\begin{array}{l}\text { Reverse } \\
\text { primer }\end{array}$ & $\begin{array}{l}\text { Annealing } \\
\text { temperature }\end{array}$ \\
\hline Lseq29 & Indel & CGCTTCTATCCTTGGTGG & AGCATTGGAGCACAGAGA & 56 \\
\hline Lseq35 & Indel & ACTCAACAGGCTAATCAGGGT & GAACAACCACTGACATCGGG & 56 \\
\hline Lseq54 & Indel & CCACCAAACAAACTAAAGAAGC & CACCCGATGACGATAAGC & 56 \\
\hline Lseq55 & Indel & CAGTTGGACGAGGGGAGTG & GAACCACAATCCTGCAGCAG & 56 \\
\hline Lseq102 & Indel & GGCTTCTTCATCATCAGGTACG & GCATGCGATCCAACCCTITG & 56 \\
\hline Lseq85 & Indel & CAGCGATGGATGCCGAAATA & САGССТАСТССТССТGСТC & 56 \\
\hline Lseq99 & Indel & TACGACCATTGCCGGATGAT & CTACATGTGGTGCTCGTACG & 56 \\
\hline Lseq100 & Indel & ATTGCGGAGTAGTGCTTCG & TAATCCTGCAATCACGAGCG & 56 \\
\hline Lseq3 & Indel & ССTCTATGTCACCCGCAAGT & CAGGGTCTCAAGTGGGGAAG & 56 \\
\hline Lseq11 & Indel & CGCTAATGGGCTGGCTTAAC & GTTCGAACCTGACACGCTG & 56 \\
\hline
\end{tabular}

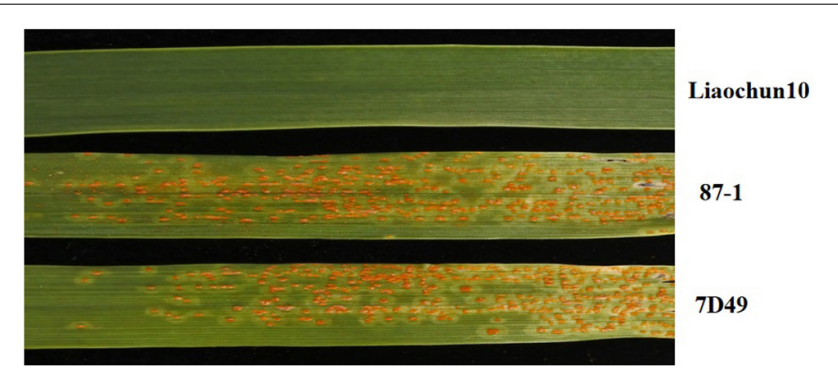

FIGURE 1 | Phenotype of resistant parent Liaochun10, susceptible parent $87-1$, and 7D49 30 days after inoculation with Pt race PHT.

frequencies to centimorgans (Kosambi, 1943) and drew the genetic map using Mapdraw v2.1 (Liu and Meng, 2003).

\section{RESULTS}

\section{Genetic Analysis of Wheat Leaf Rust Resistance Gene LrLC10 in Two Segregating Populations}

The parental lines $87-1$ and 7D49 were highly susceptible to $P t$ race PHT, [infection type $(\mathrm{IT})=3$ ], whereas Liaochun 10 was highly resistant (IT $=0$, Figure 1 ). We examined the two segregating $\mathrm{F}_{2}$ populations that grew from crossing the susceptible lines with Liaochun10. The 87-1 crossed with Liaochun 10 produced the $\mathrm{F}_{2}$ population including 3,057 plants, of which 2,300 were resistant and 757 were susceptible to $P t$ isolate PHT $\left(\chi^{2} 3: 1=0.092, P>0.05\right)$. In the $\mathrm{F}_{2}$ population derived from 7D49 crossed with Liaochun10, 624 plants were resistant and 227 were susceptible to $P t$ race $\mathrm{PHT}\left(\chi^{2} 3: 1=1.268\right.$, $P>0.05)$. These results indicated that leaf rust resistance in Liaochun10 is controlled by a single dominant gene.

\section{Allelism Test of LrLC10 and Lr13}

Liaochun10, RL4031, and the $1,395 \mathrm{~F}_{2}$ plants from the cross of Liaochun10 $\times$ RL4031 were evaluated against $P t$ race PHT. We found no susceptible plants, thus confirming that LrLC10 in Liaochun 10 was on the same locus as Lr13. Since there was Lr13 donor parents Frontanan and UP301 in the Liaochun10 pedigree (Singh and Gupta, 1991; He et al., 2001; Pathan and Park, 2006), we concluded that leaf rust resistance gene $\operatorname{LrLC10}$ in Liaochun 10 is $\operatorname{Lr} 13$.

\section{Molecular Mapping of Leaf Rust Resistance Gene LrLC10 (Lr13)}

We chose 92 extremely susceptible individuals from the $7 \mathrm{D} 49 \times$ Liaochun $10 \mathrm{~F}_{2}$ population to be re-genotyped using markers linked to LrLC10 that were established by Lv et al. (2017) (Figures 2A,B). To define the LrLC10 physical interval, we searched the sequences of all markers anchored in the genetic map against the Chinese Spring reference genomic sequence (RefSeq v1.0) and found that the relative physical positions of those markers were generally consistent with the genetic map (Figures 2B,C). Two flanking markers, CAUT163 and Xbarc18, spanned an approximately $100 \mathrm{Mb}$ region $(153,676,602-255,348,323)$ in the reference genome, and here we detected numerous sequence variations between the parents when we analyzed the re-sequencing data. Twenty indel primer pairs were designed based on those insertion/deletion polymorphisms we found between parental lines in the $11 \mathrm{Mb}(159,000,000-170,000,000)$ section that was $6 \mathrm{Mb}$ from marker CAUT163 going toward LrLC10. Among these, 4 markers (Lseq22, Lseq29, Lseq31, and Lseq35) were successfully added to the genetic map and the LrLC10 gene was delimited within a $1.65 \mathrm{cM}$ area between markers CAUT163 and Lseq22, an interval corresponding to a $5.7 \mathrm{Mb}(153,676,602-159,302,377)$ region in the CS reference genome (Figure 2C). 


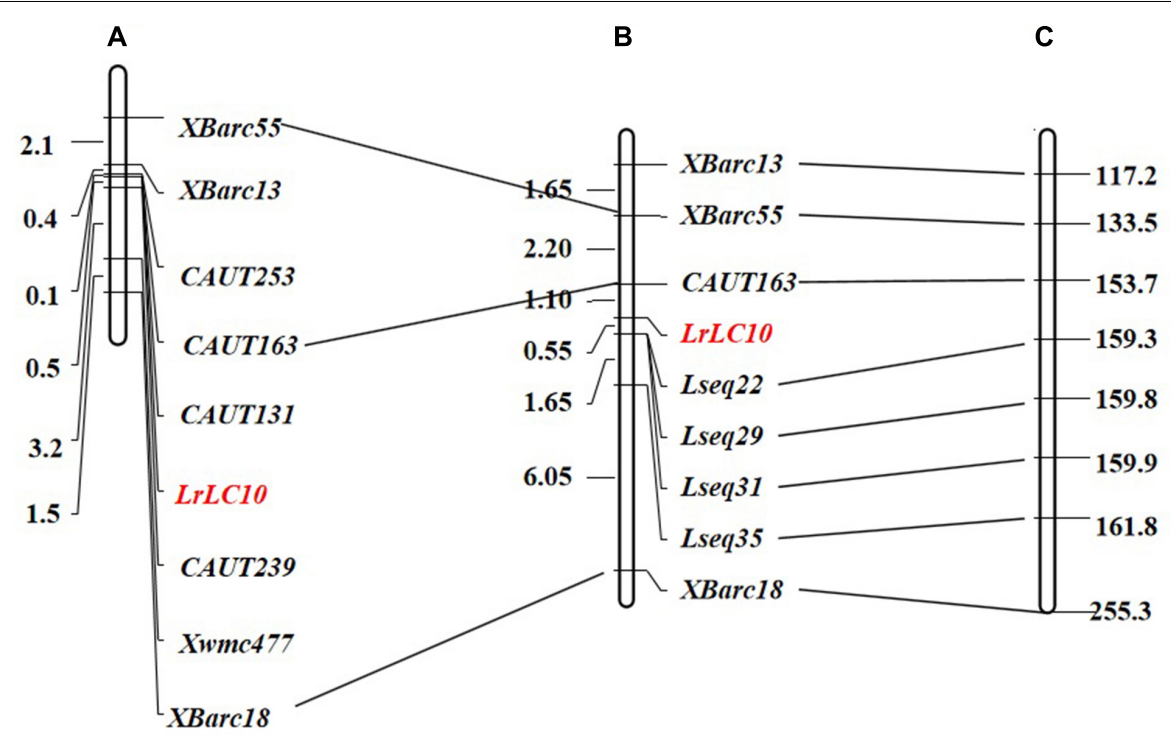

FIGURE 2 | Genetic linkage map of leaf rust resistance gene LrLC10 and corresponding physical position on the Chinese Spring RefSeq v1.0. (A) LV et al. (2017) genetic map. (B) The genetic linkage map of LrLC10, genetic distances are shown to the left in cM. (C) The corresponding physical location of the polymorphic linkage markers of $\mathrm{LrLC10}$ on the chromosome 2BS of Chinese Spring RefSeq v1.0, physical distances are shown to the right in Mb.

\section{Development of Tightly Linked Markers to LrLC10 (Lr13)}

We used those co-dominant flanking markers, CAUT163 and Lseq22, to identify recombinants in the 984 homozygous, susceptible $\mathrm{F}_{2}$ plants. Thirty-two recombinant plants were identified and then used for fine mapping of LrLC10.

Based on the parents' re-sequencing data that corresponded to the $5.7 \mathrm{Mb}$ interval of the CS RefSeq v1.0, we designed 80 indel primers and a KASP marker. They were tested on 3 parental lines and 10 markers were polymorphic between the parents and used to finely map $\operatorname{LrLC10}$ (Figure 3).

Among the 32 recombinant plants, 28 showed recombination between marker CAUT163 and $\operatorname{LrLC10}$, while 4 recombination events were detected between marker Lseq22 and LrLC10. We used the 10 polymorphic markers located between the flanking markers to examine these recombinants and found that the closest flanking markers were Lseq301 (with 1 recombination event) and Lseq85 (with 2 recombination events) and markers Lseq302 and Lseq102 co-segregated with LrLC10 (Figure 3). These results suggest that $\operatorname{LrLC10}$ locus is located in a 314.3kb region between markers Lseq 85 and Lseq301 (157,688,415158,002,717) in the CS RefSeq v1.0 (Figure 3). Markers Lseq85 and Lseq301 were designed based on the $5 \mathrm{bp}$ and $6 \mathrm{bp}$ deletions, respectively, in Liaochun10 as compared to 7D49. The KASP marker Lseq302 was based on the SNP (A/T) detected in exon 2 of TraesCS2B01G182800 between Liaochun10 and 7D49 (Figure 4A and Table 3), while Lseq102 was developed based on a 9-bp deletion in the TraesCS2B01G183000 coding region between Liaochun10 and 7D49 (Figure 4B and Table 3).

\section{Validation of LrLC10-Co-segregating Markers for Marker-Assisted Selection}

We wanted to test if these co-segregating markers (Lseq302 and Lseq102) could be used for marker-assisted selection of LrLC10 in different backgrounds. We tested 25 wheat leaf rust resistant accessions and 10 susceptible cultivars with those 2 markers to evaluate their utility. Twenty-three of the resistant accessions had the same marker genotypes as Liaochun10 and all the susceptible cultivars' genotypes were identical to 87-1 and 7D49 (Figures 5A,B and Table 1). Moreover, we found that the $F_{1}$ plants of the crosses of those 14 of the 23 resistant accessions with Xuezao, which was proved to carry the hybrid necrosis gene $\mathrm{Nel}$ (unpublished results), showed progressive necrosis (Table 1). According to Zhang et al. (2016), Lr13 and Ne2m are the same gene; so by inference, the $F_{1}$ plants' phenotypes indicate that those 14 cultivars have leaf rust resistance gene Lr13. These results suggest that markers Lseq302 and Lseq102 can be used to identify $\operatorname{Lr} 13$.

To evaluate the distribution of Lseq302-L and Lseq102-L (the marker alleles of Lseq302/Lseq102 in Liaochun10) in China, a panel of 524 common wheat accessions/landraces from China was tested with these markers. Lseq302-L and Lseq102-L always co-existed in all the cultivars, forming a specific haplotype block. The haplotype of Lseq302-L/Lseq102-L was present in various frequencies in 4 of 10 agro-ecological production zones: I, North China winter wheat region (30.76\%); II, Yellow and Huai River valleys winter wheat region (24.56\%); III, middle and lower Yangtze River valley winter wheat region (14.81\%); and V, South China winter wheat region (33.33\%) (Figure 5C and Table 4). 


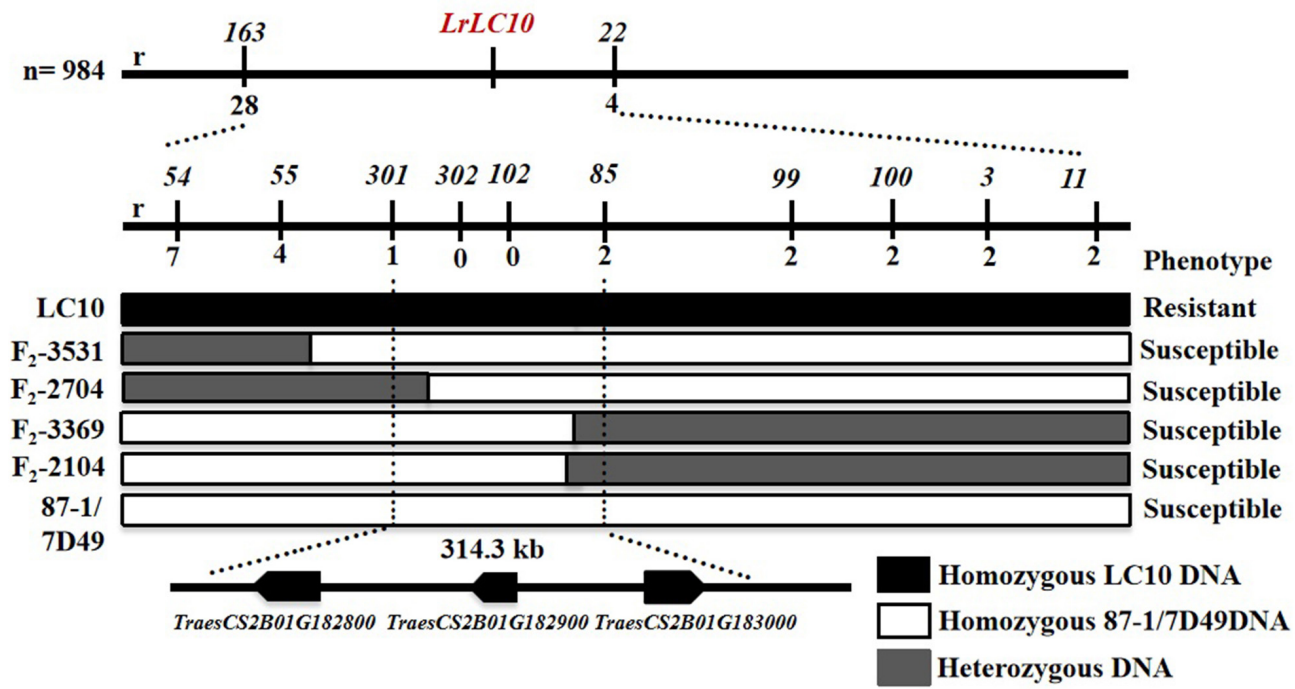

FIGURE 3 | Fine mapping of LrLC10 and three annotated genes localize in the mapping interval on Chinese Spring reference genome. Phenotypes and genotypes of four $F_{2}$ recombinants including $\left(F_{2}-3531, F_{2}-2704, F_{2}-3369, F_{2}-2104\right)$ are showed. The name and phenotype of $F_{2}$ individuals were labeled in the left and right, respectively. Black, white and gray blocks present genomic region of LC10, 87-1/7D49 and heterozygous, respectively. $r$ indicated the number of recombinants.

A

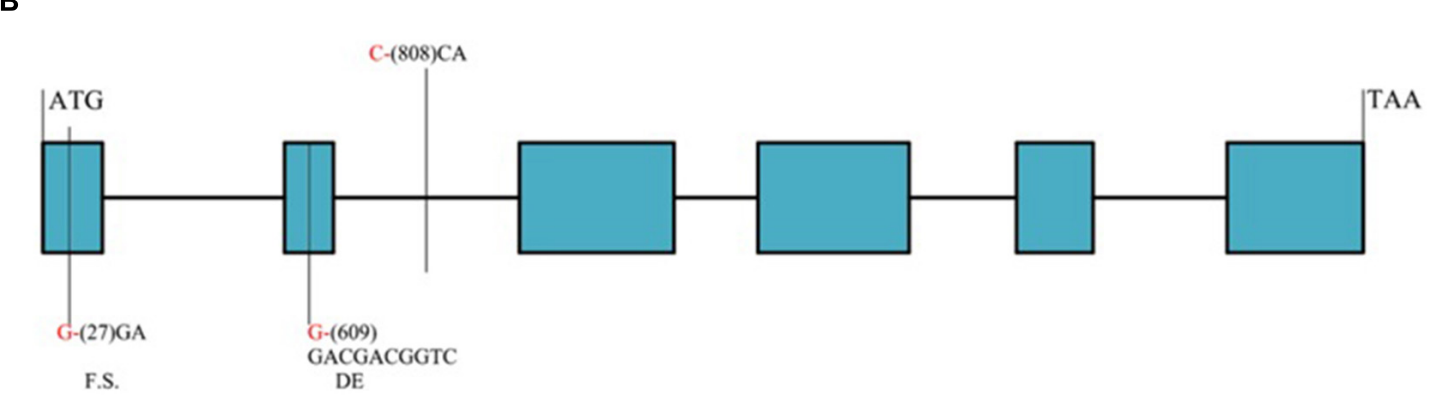

FIGURE 4 | Structure of annotated genes [TraesCS2B01G182800 and TraesCS2B01G183000 (A,B)] showing the nucleotide and amino acid sequences polymorphism between resistant and susceptible parents. Introns, exons are shown in lines, blue boxes. Red and black fonts represent resistant and susceptible parents, respectively. The numbers in bracket represent the positions of nucleotide sequences relative to ATG. F.S. represents frame shift, - indicates nucleotide deletion, IN represents amino acid insertion, DE represents amino acid deletion. 
TABLE 3 | Sequence comparison of the annotated genes.

\begin{tabular}{|c|c|c|c|c|c|}
\hline Gene-ID & Position on reference & Region of the gene & Position in the gene & $\begin{array}{l}\text { Sequence variants } \\
\text { (LC10/7D49) }\end{array}$ & $\begin{array}{c}\text { Protein variants } \\
\text { (LC10/7D49) }\end{array}$ \\
\hline \multirow[t]{40}{*}{ TraesCS2B01G182800 } & 157695820 & Exon2 & 462 & ANT & $\mathrm{S} / \mathrm{C}$ \\
\hline & 157695441 & Exon2 & 841 & $\mathrm{C} / \mathrm{T}$ & $N / S$ \\
\hline & 157695415 & Exon2 & 867 & $\mathrm{C} / \mathrm{T}$ & N/D \\
\hline & 157695245 & Exon2 & 1037 & $\mathrm{~A} / \mathrm{C}$ & $M / 1$ \\
\hline & 157695131 & Exon2 & 1151 & $A / G$ & - \\
\hline & 157694999 & Exon2 & 1283 & $\mathrm{C} / \mathrm{A}$ & - \\
\hline & 157694868 & Exon2 & 1414 & $\mathrm{G} / \mathrm{A}$ & $\mathrm{M} / \mathrm{T}$ \\
\hline & 157694755 & Exon2 & 1527 & $\mathrm{G} / \mathrm{C}$ & $\mathrm{G} / \mathrm{R}$ \\
\hline & 157694710 & Exon2 & 1572 & $\mathrm{G} / \mathrm{A}$ & $\mathrm{S} / \mathrm{P}$ \\
\hline & 157694690 & Exon2 & 1592 & $\mathrm{G} / \mathrm{A}$ & - \\
\hline & 157694468 & Exon2 & 1814 & $A / G$ & - \\
\hline & 157694465 & Exon2 & 1817 & $\mathrm{G} / \mathrm{A}$ & - \\
\hline & 157694447 & Exon2 & 1835 & $\mathrm{G} / \mathrm{A}$ & - \\
\hline & 157694427 & Exon2 & 1855 & $\mathrm{~A} / \mathrm{T}$ & $\mathrm{Y} / \mathrm{F}$ \\
\hline & 157694415 & Exon2 & 1867 & $\mathrm{G} / \mathrm{T}$ & $E / A$ \\
\hline & 157694404 & Exon2 & 1878 & $\mathrm{C} / \mathrm{T}$ & $S / G$ \\
\hline & 157694391 & Exon2 & 1891 & $\mathrm{G} / \mathrm{C}$ & $\mathrm{C} / \mathrm{S}$ \\
\hline & 157694334 & Exon2 & 1948 & $\mathrm{C} / \mathrm{T}$ & $\mathrm{K} / \mathrm{R}$ \\
\hline & 157694248 & Exon2 & 2034 & $\mathrm{~T} / \mathrm{A}$ & $\mathrm{S} / \mathrm{T}$ \\
\hline & 157694141 & Exon2 & 2141 & $T / G$ & - \\
\hline & 157694095 & Exon2 & 2187 & $\mathrm{C} / \mathrm{T}$ & $\mathrm{K} / \mathrm{E}$ \\
\hline & 157693616 & Exon2 & 2666 & G-/GCTA & Insertion \\
\hline & 157693556 & Exon2 & 2726 & $\mathrm{G} / \mathrm{A}$ & - \\
\hline & 157693457 & Exon2 & 2825 & $\mathrm{C} / \mathrm{G}$ & $\llcorner/ F$ \\
\hline & 157693411 & Exon2 & 2871 & $\mathrm{G} / \mathrm{T}$ & $\mathrm{H} / \mathrm{N}$ \\
\hline & 157693396 & Exon2 & 2886 & $\mathrm{C} / \mathrm{T}$ & $\mathrm{A} / \mathrm{T}$ \\
\hline & 157693385 & Exon2 & 2897 & $A / G$ & - \\
\hline & 157693336 & Exon2 & 2946 & $T / G$ & $\mathrm{~N} / \mathrm{H}$ \\
\hline & 157693331 & Exon2 & 2951 & $\mathrm{~A} / \mathrm{C}$ & $\mathrm{C} / \mathrm{W}$ \\
\hline & 157692236 & Intron2 & 4046 & $\mathrm{~T} / \mathrm{C}$ & - \\
\hline & 157692035 & Intron2 & 4247 & $\mathrm{C} / \mathrm{T}$ & - \\
\hline & 157691555 & Intron2 & 4727 & $A / G$ & - \\
\hline & 157691227 & Intron2 & 5055 & $A / G$ & - \\
\hline & 157691178 & Intron2 & 5104 & $\mathrm{C} / \mathrm{T}$ & - \\
\hline & 157691106 & Intron2 & 5176 & $\mathrm{C} / \mathrm{T}$ & - \\
\hline & 157691012 & Intron2 & 5270 & $\mathrm{G} / \mathrm{A}$ & - \\
\hline & 157690905 & Intron2 & 5377 & $\mathrm{~T} / \mathrm{C}$ & - \\
\hline & 157690902 & Intron2 & 5380 & $\mathrm{~T} / \mathrm{C}$ & - \\
\hline & 157690874 & Intron2 & 5408 & $A / G$ & - \\
\hline & 157690808 & Intron2 & 5474 & $\mathrm{~T} / \mathrm{C}$ & - \\
\hline
\end{tabular}


TABLE 3 | Continued

\begin{tabular}{|c|c|c|c|c|c|}
\hline Gene-ID & Position on reference & Region of the gene & Position in the gene & $\begin{array}{c}\text { Sequence variants } \\
\text { (LC10/7D49) }\end{array}$ & $\begin{array}{c}\text { Protein variants } \\
\text { (LC10/7D49) }\end{array}$ \\
\hline & 157690406 & Intron2 & 5876 & $\mathrm{C} / \mathrm{T}$ & - \\
\hline & 157690397 & Intron2 & 5885 & $\mathrm{G} / \mathrm{A}$ & - \\
\hline & 157690385 & Intron2 & 5897 & $\mathrm{~T} / \mathrm{C}$ & - \\
\hline & 157690201 & Intron2 & 6081 & $\mathrm{C} / \mathrm{T}$ & - \\
\hline & 157690155 & Intron2 & 6127 & $\mathrm{~A} / \mathrm{G}$ & - \\
\hline & 157689837 & Intron2 & 6445 & $A / G$ & - \\
\hline & 157689423 & Intron2 & 6859 & AT/A- & - \\
\hline & 157689364 & Intron2 & 6918 & $\mathrm{G} / \mathrm{A}$ & - \\
\hline \multirow[t]{3}{*}{ TraesCS2B01G183000 } & 157755306 & Exon1 & 27 & G-/GA & Frame shift \\
\hline & 157755888 & Exon2 & 609 & G-/GACGACGGTC & Deletion \\
\hline & 157756087 & Intron2 & 808 & $\mathrm{C}-/ \mathrm{CA}$ & - \\
\hline
\end{tabular}

Position in the gene represents the positions of nucleotide sequences relative to ATG.

A

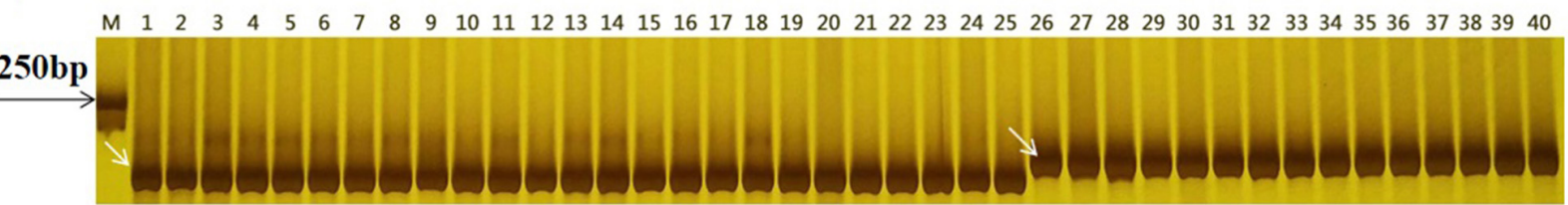

B

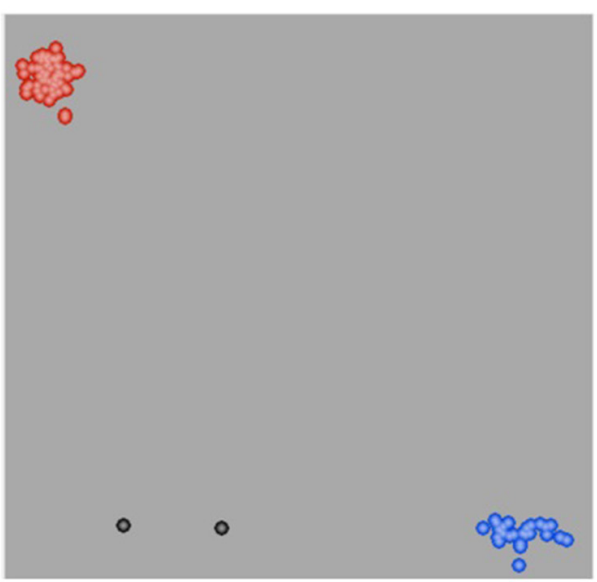

C

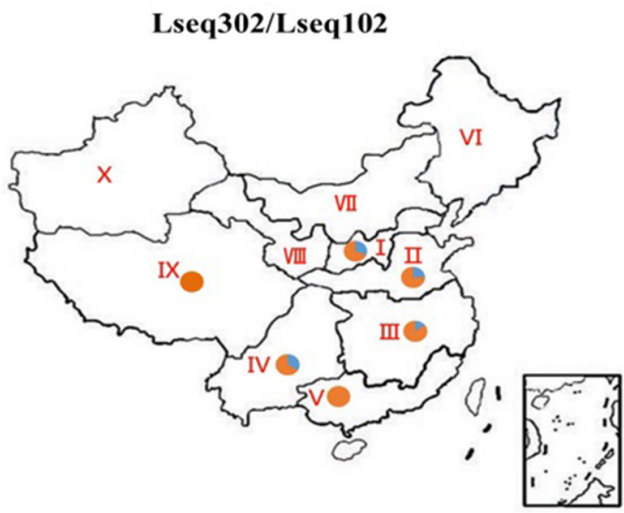

Resistant haplotype

Susceptible haplotype

FIGURE 5 | Validation of Lr13 diagnostic markers (A,B) and haplotype distribution of Lseq302 and Lseq102 in 524 common wheat cultivars/landraces from China (C). A co-segregated marker Lseq102 genotyped several Lr13 carriers and susceptible accessions in PAGE gel. The number 1 and 24 present Liaochun10 and 87-1, respectively, 2-23, 25-31 indicate Lr13 carriers and susceptible lines, respectively. M: Marker; B plots of KASP marker Lseq302 tested 23 Lr13 carriers (blue dots), 10 susceptible lines (red dots) and other cultivars with unknown leaf rust resistance. Black dots are water controls; C I, north China winter wheat region; II, Yellow and Huai River valley winter wheat region; III, middle and lower Yangtze River valley winter wheat region; IV, south-western winter wheat region; V, south China winter wheat region; VI, north-eastern spring wheat region; VII, northern spring wheat region; VIII, north-western spring wheat region; IX, Qinghai-Tibet spring-winter wheat region; $X$, Xinjiang winter-spring wheat region.

\section{DISCUSSION}

Seven leaf rust resistance genes $(\operatorname{Lr} 13, \operatorname{Lr} 16, \operatorname{Lr} 23, \operatorname{Lr} 35, \operatorname{Lr} 48$, $L r 73$, and $L r Z H 22$ ) had been mapped on wheat chromosome 2BS (Seyfarth et al., 1999; Park et al., 2014; Nsabiyera et al., 2016; Wang et al., 2016; Zhang et al., 2016; Chhetri et al., 2017; Kassa et al., 2017). We found that LrLC10 is located in the region 157,688,415-158,002,717 bp (Figure 3) (2BS1-0.53-0.75) on the reference sequence of Chinese Spring (RefSeq v1.0). Of those $7 \mathrm{Lr}$ genes, only $\operatorname{Lr} 13$ and $\mathrm{LrZH} 22$ were reported to be located in the same region as LrLC10 (Wang et al., 2016; Zhang et al., 2016). LrZH22 confers resistance to leaf rust at both the seedling and adult stages (Wang et al., 2016), whereas resistance gained from LrLC10 is effective only after the four-leaf stage. Up to now, the relationship between LrLC10 and Lr13 was unknown, but we confirmed that LrLC10 


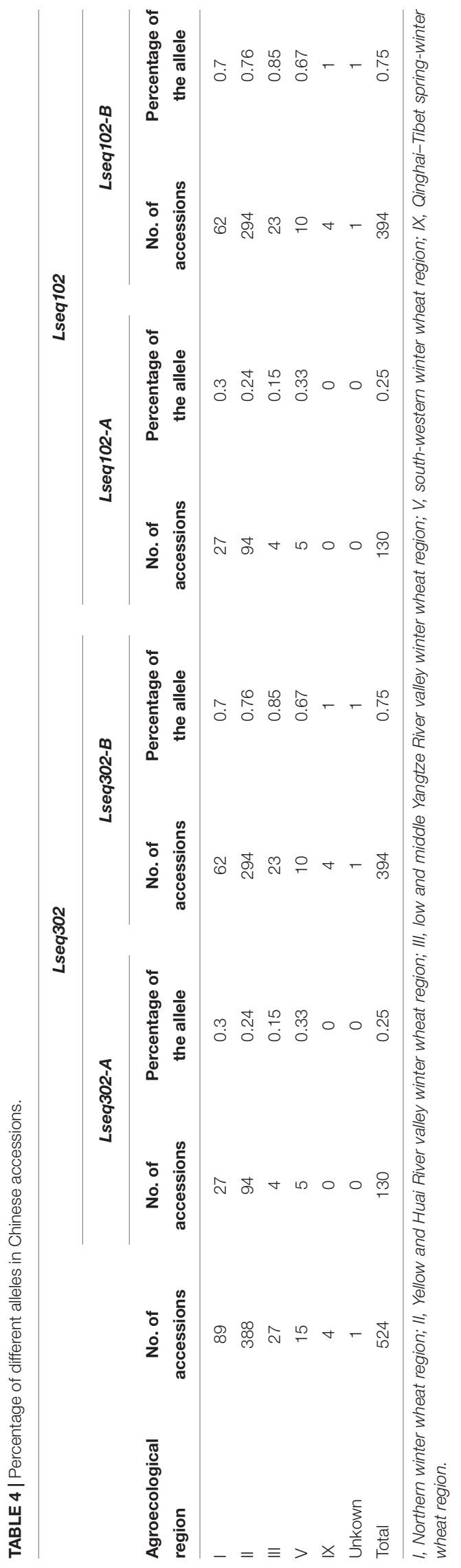

is Lr13. The pedigree of Liaochun10 is 1048 (Ke71F $4370-$ 10/Mexipak66//UP301) $\times$ Liao70181-2 (Liaochun6/Jinghong1) and the parents of Liaochun6 are Frontana and Liaochun1 (He et al., 2001). Since the leaf rust resistance gene in Frontana and UP301 is Lr13 (Singh and Gupta, 1991; Pathan and Park, 2006), the leaf rust resistance gene in Liaochun 10 may be derived from the Frontana or UP301 parent.

In the process of fine mapping $\operatorname{LrLC10}$, enough polymorphic markers were found to narrow down the genetic interval covering the targeted gene. We accomplished this by re-sequencing the parental lines and developing indel and SNP markers based on sequence information in the targeted region. Four indel markers revealed polymorphisms and localized $\operatorname{LrLC10}$ gene in a $1.65 \mathrm{cM}$ genetic interval, which corresponded to a $5.7 \mathrm{Mb}$ interval on the Chinese Spring reference genomic sequence (Figures 2B,C). Based on sequence diversities between the parental lines on the candidate interval, we designed 9 indel markers and a KASP marker and used these to test the 32 recombinants that we identified using LrLC10-flanking markers CAUT163 and Lseq 22 derived from 984 homozygous, susceptible $\mathrm{F}_{2}$ individuals. LrLC10 was finally delimited into a $314.3-\mathrm{kb}$ genomic interval on the Chinese Spring reference sequence v1.0 by markers Lseq301 and Lseq85 (Figure 3). This mapping of LrLC10 demonstrated our methods efficiently developed molecular markers based from the re-sequencing data of the parents.

Lr13 is one of the most widely distributed leaf rust resistance genes in wheat (McIntosh et al., 1995), but it has become ineffective in some regions, such as Mexico and South America (Singh and Rajaram, 1992). However, it is effective in combination with other resistance genes, such as Lr3ka, Lr34, and Lr16 (Kolmer, 1992). Therefore, we need diagnostic molecular markers for Lr13 to facilitate selection or stacking it with other $L r$ genes. In our study, KASP marker Lseq302 and indel marker Lseq102 co-segregated with $\operatorname{Lr} 13$ and were effective in diverse wheat backgrounds (Figures 5A,B, Table 1, and Supplementary Table S1). Therefore, these diagnostic markers may be used for efficient marker-assisted selection of Lr13, thus enabling researchers to either pyramid it with other adult plant resistant genes to achieve durable leaf rust resistance or stack it with stripe rust, stem rust, and powdery mildew resistance genes (e.g., Yr27, Sr40, and pm42) on chromosome 2BS, to create multiresistance accessions (McDonald et al., 2004; Hua et al., 2009; Wu et al., 2009).

To date, several leaf rust resistance genes have been isolated in wheat: $\operatorname{Lr} 1, \operatorname{Lr} 10, \operatorname{Lr} 21, \operatorname{Lr} 34, \operatorname{Lr} 67$, and $\operatorname{Lr} 22 a$ (Feuillet et al., 2003; Huang et al., 2003; Cloutier et al., 2007; Krattinger et al., 2009; Moore et al., 2015; Thind et al., 2017). Among those genes, Lr34 encodes an ATP-binding cassette transporter that carries resistance-related metabolites that affect the growth of pathogenic bacteria (Krattinger et al., 2009). Lr67 encodes a hexose transporter, LR67res, that through heterodimerization with the Lr67- susceptible functional transporter LR67sus, exerted a dominant-negative effect that restricted the growth of multiple biotrophic pathogens by reducing their glucose uptake (Moore et al., 2015). Lr34 and Lr67 provide wheat with resistance to multiple fungal pathogens. The others are typical resistance 
genes with nucleotide-binding site leucine-rich repeat (NBSLRR) domains (Feuillet et al., 2003; Huang et al., 2003; Cloutier et al., 2007; Thind et al., 2017). However, $\operatorname{LrLC10}$ ( $\operatorname{Lr13}$ ) was shown to be a race-specific resistance gene (Dyck et al., 1966), thus it most likely has the R-gene structure of NLR.

In this study, we delimited $\operatorname{LrLC10}$ to a $314.3 \mathrm{~kb}$ region on short arm of chromosome $2 \mathrm{~B}$ in Chinese Spring reference genome sequence (RefSeq v1.0). Three high confidence genes (TraesCS2B01G182800, TraesCS2B01G182900, and TraesCS2B01G183000) have different functions based on the annotation of Chinese Spring reference genome ${ }^{7}$, which encode a typical NBS-LRR protein, Ribonuclease, and an F-box domain containing Leucine-rich repeats protein were located in this region. DNA sequence comparison showed that the parents did not differ in TraesCS2B01G182900. Compared to 7D49, Liaochun10 had a 9 bp deletion in its TraesCS2B01G183000 coding region, resulting in a deletion of three amino acids, and another 1-bp deletion that led to a translational frame shift (Figure 4B and Table 3). In TraesCS2B01G182800, we found many sequence variations, including 56 SNPs and 4 indels, between Liaochun 10 and its rust-susceptible parent. Among them, we found 18 SNPs and one indel in the intron region, and 38 SNPs and three indels in exon 2. Among those 38 SNPs, 26 caused amino acid substitutions, and two of the indels led to a translational frame shift. A 3-bp insertion in 7D49 resulted in an amino acid insertion that was not found in Liaochun 10 (Figure 4A and Table 3). Based on the TraesCS2B01G182800 and TraesCS2B01G183000 sequence polymorphisms between the parental lines, we developed the markers Lseq102 and Lseq302 and found that they co-segregated with $\operatorname{LrLC10}$ (Figure 3). In total, our results suggest that $\operatorname{LrLC10}$ ( $\operatorname{rr13}$ ) might be one of those two annotated genes. However, there is still a chance that the sequence corresponding to $\operatorname{LrLC} 10$ is absent in the CS genomic sequence. Therefore, our analysis of re-sequencing data based on the wheat reference genome sequence is not enough to be absolutely certain of its identity. Because of this, a library of the resistant parent must be constructed so that a physical map would enable the cloning of $\operatorname{LrLC10}$. Recently, some alternative methods (e.g., MutRenSeq, TACCA, and MutChromSeq) have been used to clone wheat disease resistance genes

${ }^{7}$ https://urgi.versailles.inra.fr/download/iwgsc/IWGSC_RefSeq_Annotations/ $\mathrm{v} 1.0 /$

\section{REFERENCES}

Anand, D., Saini, R. G., and Gupta, A. K. (1991). Linkage distance between the wheat leaf rust resistance gene $\operatorname{Lr} 13$ and a gene for hybrid necrosis $\mathrm{Ne} 2 \mathrm{~m}$. J. Genet. Breed. 45, 245-246.

Bansal, U. K., Hayden, M. J., Venkata, B. P., Khanna, R., Saini, R. G., Bariana, H. S., et al. (2008). Genetic mapping of adult plant leaf rust resistance genes $L r 48$ and Lr49 in common wheat. Theor. Appl. Genet. 117, 307-312. doi: 10.1007/s00122008-0775-6

Bariana, H. S., Brown, G. N., Bansal, U. K., Miah, H., Standen, G. E., and Lu, M. (2007). Breeding triple rust resistant wheat cultivars for Australia using conventional and marker-assisted selection technologies. Aust. J. Agric. Res. 58, 576-587. doi: 10.1071/AR07124

Chai, L., Chen, Z., Bian, R., Zhai, H., Cheng, X., Peng, H., et al. (2018). Dissection of two quantitative trait loci with pleiotropic effects on plant height and spike
(Steuernagel et al., 2016; Sánchez-Martín et al., 2016; Thind et al.,

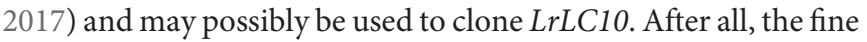
genetic map and co-segregating markers developed in our present study may aid the map-based cloning and the marker-assisted selection of $\operatorname{LrLC10}$ ( $\operatorname{rr13})$.

\section{DATA AVAILABILITY STATEMENT}

The datasets generated for this study can be found in the European Variation Archive (EVA) using accession number PRJEB37197.

\section{AUTHOR CONTRIBUTIONS}

LQ and CX conceived the project. LQ, HW, WW, YuL, and JMu performed the experiments. MG and YiL assisted in revising the manuscript. WG analyzed the re-sequencing data. JMa, $\mathrm{ZH}$, and QS provided materials. LQ wrote the manuscript. CX revised the manuscript.

\section{FUNDING}

This work was financially supported by the National Key Research and Development Project of China 2016YFD0101802) and National Natural Science Foundation of China (31671676 and 31872865).

\section{ACKNOWLEDGMENTS}

We are grateful to Dr. Zhen Wang for assistance in revising the manuscript; Dr. Xiaobo Wang for providing the DNA of 524 Chinese wheat accessions/landraces.

\section{SUPPLEMENTARY MATERIAL}

The Supplementary Material for this article can be found online at: https://www.frontiersin.org/articles/10.3389/fpls.2020.00470/ full\#supplementary-material

length linked in coupling phase on the short arm of chromosome $2 \mathrm{D}$ of common wheat (Triticum aestivum L.). Theor. Appl. Genet. 131, 2621-2637. doi: 10.1007/s00122-018-3177-4

Chen, J. W., Wang, L., Pang, X. F., and Pan, Q. H. (2006). Genetic analysis and fine mapping of a rice brown planthopper (Nilaparvata lugens Stål) resistance gene bph19(t). Mol. Genet. Genomics 275, 321-329. doi: 10.1007/s00438-005-0088-2

Chhetri, M., Bariana, H., Wong, D., Sohail, Y., Hayden, M., and Bansal, U. (2017). Development of robust molecular markers for marker-assisted selection of leaf rust resistance gene $\operatorname{Lr} 23$ in common and durum wheat breeding programs. Mol. Breed. 37:21. doi: 10.1007/s11032-017-0628-6

Clavijo, B. J., Venturini, L., Schudoma, C., Accinelli, G. G., Kaithakottil, G., Wright, J., et al. (2017). An improved assembly and annotation of the allohexaploid wheat genome identifies complete families of agronomic genes and provides genomic evidence for chromosomal translocations. Genome Res. 27, 885-896. doi: $10.1101 /$ gr.217117.116 
Cloutier, S., McCallum, B. D., Loutre, C., Banks, T. W., Wicker, T., Feuillet, C., et al. (2007). Leaf rust resistance gene $\operatorname{Lr} 1$, isolated from bread wheat (Triticum aestivum L.) is a member of the large psr567 gene family. Plant Mol. Biol. 65, 93-106. doi: 10.1007/s11103-007-9201-8

Dong, J. G. (2001). Agricultural Plant Pathology. Beijing: China Agriculture Press.

Dou, B., Hou, B., Xu, H., Lou, X., Chi, X., Yang, J., et al. (2009). Efficient mapping of a female sterile gene in wheat (Triticum aestivum L.). Genet. Res. 91, 337-343. doi: 10.1017/S0016672309990218

Dyck, P. L., Samborski, D. J., and Anderson, R. G. (1966). Inheritance of adultplant leaf rust resistance derived from the common wheat varieties Exchange and Frontana. Can. J. Genet. Cytol. 8, 665-671. doi: 10.1139/g66-082

FAOSTAT (2015). FAO statistical Pocketbook 2015: World Food and Agriculture. Rome: Food and Agriculture Organization of the United Nations.

Feng, J., Chen, G., Wei, Y., Liu, Y., Jiang, Q., Li, W., et al. (2015). Identification and mapping stripe rust resistance gene $\operatorname{YrLM168a}$ using extreme individuals and recessive phenotype class in a complicate genetic background. Mol. Genet. Genomics 290, 2271-2278. doi: 10.1007/s00438-015-1077-8

Feuillet, C., Travella, S., Stein, N., Albar, L., Nublat, A., and Keller, B. (2003). Map-based isolation of the leaf rust disease resistance gene Lr10 from the hexaploid wheat (Triticum aestivum L.) genome. Proc. Natl. Acad. Sci. U.S.A. 100, 15253-15258. doi: 10.1073/pnas.2435133100

He, Z. H., Rajaram, S., and Huang, G. Z. (2001). A History of Wheat Breeding in China. Mexico City: CIMMYT.

Hua, W., Liu, Z., Zhu, J., Xie, C., Yang, T., Zhou, Y., et al. (2009). Identification and genetic mapping of $p m 42$, a new recessive wheat powdery mildew resistance gene derived from wild emmer (Triticum turgidum var. dicoccoides). Theor. Appl. Genet. 119, 223-230. doi: 10.1007/s00122-009-1031-4

Huang, L., Brooks, S. A., Li, W., Fellers, J. P., Trick, H. N., and Gill, B. S. (2003). Map-Based cloning of leaf rust resistance gene Lr21 from the large and polyploid genome of bread wheat. Genetics 164, 655-664.

Jiang, B., Liu, T., Li, H., Han, H., Li, L., Zhang, J., et al. (2018). Physical mapping of a novel locus conferring leaf rust resistance on the long arm of Agropyron cristatum Chromosome 2P. Front. Plant Sci. 9:817. doi: 10.3389/fpls.2018.00817

Kassa, M. T., You, F. M., Hiebert, C. W., Pozniak, C. J., Fobert, P. R., Sharpe, A. G., et al. (2017). Highly predictive SNP markers for efficient selection of the wheat leaf rust resistance gene Lr16. BMC Plant Biol. 17:45. doi: 10.1186/s12870-0170993-7

Kiswara, G., Lee, J. H., Hur, Y. J., Cho, J. H., Lee, J. Y., Kim, S. Y., et al. (2014). Genetic analysis and molecular mapping of low amylose gene $d u 12(\mathrm{t})$ in rice (Oryza sativa L.). Theor. Appl. Genet. 127, 51-57. doi: 10.1007/s00122-0132200-z

Kolmer, J. A. (1992). Enhanced leaf rust resistance in wheat conditioned by resistance gene pairs with Lr13. Euphytica 61, 123-130. doi: 10.1007/ BF00026802

Kolmer, J. A., Su, Z., Bernardo, A., Bai, G., and Chao, S. (2018). Mapping and characterization of the new adult plant leaf rust resistance gene $\operatorname{Lr} 77$ derived from Santa Fe winter wheat. Theor. Appl. Genet. 131, 1553-1560. doi: 10.1007/ s00122-018-3097-3

Kosambi, D. D. (1943). The estimation of map distance from recombination values. Ann. Eugen. 12, 172-175. doi: 10.1111/j.1469-1809.1943.tb02321.x

Krattinger, S. G., Lagudah, E. S., Spielmeyer, W., Singh, R. P., Huerta-Espino, J., McFadden, H., et al. (2009). A putative ABC transporter confers durable resistance to multiple fungal pathogens in wheat. Science 323, 1360-1363. doi: $10.1126 /$ science. 1166453

Liu, R., and Meng, J. (2003). MapDraw: a microsoft excel macro for drawing genetic linkage maps based on given genetic linkage data. Hereditas 25, 317-321. doi: 10.16288/j.yczz.2003.03.017

Lv, X., Tang, H., Geng, M., Mi, Y., Li, Y., Li, F., et al. (2017). Comparative genomics analysis of leaf rust resistance gene $\mathrm{LrLC10}$ in common wheat cultivar Liaochun10. J. China Agric. Univ. 22, 01-09.

McDonald, D. B., McIntosh, R. A., Wellings, C. R., Singh, R. P., and Nelson, J. C. (2004). Cytogenetical studies in wheat XIX. location and linkage studies on gene Yr27 for resistance to stripe (yellow) rust. Euphytica 136, 239-248. doi: 10.1023/B:EUPH.0000032709.59324.45

McIntosh, R. A., Dubcovsky, J., Rogers, W. J., Morris, C., and Xia, X. (2017). Catalogue of Gene Symbols for Wheat: 2017 Supplement. Avaliable at: https://shigen.nig.ac.jp/wheat/komugi/genes/macgene/supplement 2017.pdf. (accessed September 20, 2017).
McIntosh, R. A., Wellings, C. R., and Park, R. F. (1995). Wheat Rusts: An Atlas of Resistance Genes. Melbourne: Csiro Publishing.

Mei, M. H., Dai, X. K., Xu, C. G., and Zhang, Q. (1999). Mapping and genetic analysis of the genes for photoperiod-sensitive genic male sterility in rice using the original mutant Nongken 58S. Crop Sci. 39, 1711-1715. doi: 10.2135/ cropsci1999.3961711x

Michelmore, R. W., Paran, I., and Kesseli, R. V. (1991). Identification of markers linked to disease-resistance genes by bulked segregant analysis: a rapid method to detect markers in specific genomic regions by using segregating populations. Proc. Natl. Acad. Sci. U.S.A. 88, 9828-9832. doi: 10.1073/pnas.88.21.9828

Moore, J. W., Herrera-Foessel, S., Lan, C., Schnippenkoetter, W., Ayliffe, M., Huerta-Espino, J., et al. (2015). A recently evolved hexose transporter variant confers resistance to multiple pathogens in wheat. Nat. Genet. 47, 1494-1498. doi: $10.1038 /$ ng.3439

Narang, D., Kaur, S., Steuernagel, B., Ghosh, S., Dhillon, R., Bansal, M., et al. (2019). Fine mapping of Aegilops peregrina co-segregating leaf and stripe rust resistance genes to distal-most end of 5DS. Theor. Appl. Genet. 132, 1473-1485. doi: 10.1007/s00122-019-03293-5

Nsabiyera, V., Qureshi, N., Bariana, H. S., Wong, D., Forrest, K. L., Hayden, M. J., et al. (2016). Molecular markers for adult plant leaf rust resistance gene $\mathrm{Lr} 48$ in wheat. Mol. Breed. 36:65. doi: 10.1007/s11032-016-0488-5

Park, R. F., Mohler, V., Nazari, K., and Singh, D. (2014). Characterisation and mapping of gene Lr73 conferring seedling resistance to Puccinia triticina in common wheat. Theor. Appl. Genet. 127, 2041-2049. doi: 10.1007/s00122-0142359-y

Pathan, A. K., and Park, R. F. (2006). Evaluation of seedling and adult plant resistance to leaf rust in European wheat cultivars. Euphytica 149, 327-342. doi: 10.1007/s10681-005-9081-4

Qureshi, N., Bariana, H., Kumran, V. V., Muruga, S., Forrest, K. L., Hayden, M. J., et al. (2018). A new leaf rust resistance gene $\operatorname{Lr} 79$ mapped in chromosome 3BL from the durum wheat landrace Aus26582. Theor. Appl. Genet. 131, 1091-1098. doi: 10.1007/s00122-018-3060-3

Ren, X., Liu, T., Liu, B., Gao, L., and Chen, W. Q. (2015). Postulation of seedling leaf rust resistance genes in 84 Chinese winter wheat cultivars. J. Integrat. Agric. 14, 1992-2001. doi: 10.1016/S2095-3119(14)61002-9

Roelfs, A. P. (1988). Resistance to Leaf and Stem Rusts in Wheat. Breeding Strategies for Resistance to the Rusts of Wheat. Mexico: CIMMYT.

Roelfs, A. P., Singh, R. P., and Saari, E. E. (1992). Rust Diseases of Wheat: Concepts and Methods of Disease Management. Mexico: CIMMYT.

Sánchez-Martín, J., Steuernagel, B., Ghosh, S., Herren, G., Hurni, S., Adamski, N., et al. (2016). Rapid gene isolation in barley and wheat by mutant chromosome sequencing. Genome Biol. 17:221. doi: 10.1186/s13059-016-1082-1

Seyfarth, R., Feuillet, C., Schachermayr, G., Winzeler, M., and Keller, B. (1999). Development of a molecular marker for the adult plant leaf rust resistance gene Lr35 in wheat. Theor. Appl. Genet. 99, 554-560. doi: 10.1007/s00122005 1268

Singh, A., Knox, R. E., DePauw, R. M., Singh, A. K., Cuthbert, R. D., Campbell, H. L., et al. (2013). Identification and mapping in spring wheat of genetic factors controlling stem rust resistance and the study of their epistatic interactions across multiple environments. Theor. Appl. Genet. 126, 1951-1964. doi: 10. 1007/s00122-013-2109-6

Singh, R. P., Chen, W. Q., and He, Z. H. (1999). Leaf rust resistance of spring, facultative, and winter wheat cultivars from china. Plant Dis. 83, 644-651. doi: 10.1094/PDIS.1999.83.7.644

Singh, R. P., and Gupta, A. K. (1991). Genes for leaf rust resistance in Indian and Pakistani wheats tested with Mexican pathotypes of Puccinia recondita f. sp. tritici. Euphytica 57, 27-36. doi: 10.1007/BF00040475

Singh, R. P., and Rajaram, S. (1992). Genetics of adult-plant resistance of leaf rust in 'Frontana' and three CIMMYT wheats. Genome 35, 24-31. doi: 10.1139/g92004

Steuernagel, B., Periyannan, S. K., Hernández-Pinzón, I., Witek, K., Rouse, M. N., $\mathrm{Yu}, \mathrm{G}$., et al. (2016). Rapid cloning of disease-resistance genes in plants using mutagenesis and sequence capture. Nat. Biotechnol. 34, 652-655. doi: 10.1038/ nbt. 3543

Thind, A. K., Wicker, T., Šimková, H., Fossati, D., Moullet, O., Brabant, C., et al. (2017). Rapid cloning of genes in hexaploid wheat using cultivar-specific longrange chromosome assembly. Nat. Biotechnol. 35, 793-796. doi: 10.1038/nbt. 3877 
Varshney, R. K., Terauchi, R., and McCouch, S. R. (2014). Harvesting the promising fruits of genomics: applying genome sequencing technologies to crop breeding. PLoS Biol. 12:e1001883. doi: 10.1371/journal.pbio.1001883

Wang, C., Yin, G., Xia, X., He, Z., Zhang, P., Yao, Z., et al. (2016). Molecular mapping of a new temperature-sensitive gene $\mathrm{LrZH} 22$ for leaf rust resistance in Chinese wheat cultivar Zhoumai 22. Mol. Breed. 36:18. doi: 10.1007/s11032016-0437-3

WAP (2017). "World agricultural production," in Circular Series, WAP 0117, Washington, DC: United States Department of Agriculture-Foreign Agricultural Service.

Wu, J., Liu, S., Wang, Q., Zeng, Q., Mu, J., Huang, S., et al. (2018a). Rapid identification of an adult plant stripe rust resistance gene in hexaploid wheat by high-throughput SNP array genotyping of pooled extremes. Theor. Appl. Genet. 131, 43-58. doi: 10.1007/s00122-017-2984-3

Wu, J., Zeng, Q., Wang, Q., Liu, S., Yu, S., Mu, J., et al. (2018b). SNP-based pool genotyping and haplotype analysis accelerate fine-mapping of the wheat genomic region containing stripe rust resistance gene Yr26. Theor. Appl. Genet. 131, 1481-1496. doi: 10.1007/s00122-018-3092-8

Wu, P., Hu, J., Zou, J., Qiu, D., Qu, Y., Li, Y., et al. (2019). Fine mapping of the wheat powdery mildew resistance gene Pm52 using comparative genomics analysis and the Chinese Spring reference genomic sequence. Theor. Appl. Genet. 132, 1451-1461. doi: 10.1007/s00122-019-03291-7

Wu, S., Pumphrey, M., and Bai, G. (2009). Molecular mapping of stem-rustresistance gene in wheat. Crop Sci. 49:1681. doi: 10.2135/cropsci2008.11. 0666

Xu, Y., Li, P., Zou, C., Lu, Y., Xie, C., Zhang, X., et al. (2017). Enhancing genetic gain in the era of molecular breeding. J. Exp. Bot. 68, 2641-2666. doi: 10.1093/ jxb/erx135

Yao, F., Xu, C., Yu, S., Li, J., Gao, Y., Li, X., et al. (1997). Mapping and genetic analysis of two fertility restorer loci in the wild-abortive cytoplasmic male sterility system of rice (Oryza sativa L.). Euphytica 98, 183-187. doi: 10.1023/A: 1003165116059

Yuan, J., and Chen, W. (2011). Estimate on the effectiveness of main resistant genes for leaf rust in Chinese Wheat. J. Triticeae Crops 31, 994-999.
Yuan, J., Liu, T., and Chen, W. (2007). Postulation of leaf rust resistance genes in 47 new wheat cultivars (lines) at seedling stage cultivars (lines) at seedling stage. Sci. Agric. Sinica 40, 1925-1935.

Zhang, P., Gebrewahid, T. W., Zhou, Y., Li, Q., Li, Z., and Liu, D. (2019). Seedling and adult plant resistance to leaf rust in 46 Chinese bread wheat landraces and 39 wheat lines with known Lr genes. J. Integrat. Agric. 18, 1014-1023. doi: 10.1016/S2095-3119(19)62575-X

Zhang, P., Hiebert, C. W., McIntosh, R. A., McCallum, B. D., Thomas, J. B., Hoxha, S., et al. (2016). The relationship of leaf rust resistance gene $\operatorname{Lr} 13$ and hybrid necrosis gene Ne2m on wheat chromosome 2BS. Theor. Appl. Genet. 129, 485-493. doi: 10.1007/s00122-015-2642-6

Zhang, Q., Shen, B. Z., Dai, X. K., Mei, M. H., Maroof, M. A. S., and Li, Z. (1994). Using bulked extremes and recessive class to map genes for photoperiodsensitive genic male sterility in rice. Proc. Natl. Acad. Sci. U.S.A 91, 8675-8679. doi: 10.1073/pnas.91.18.8675

Zhou, H., Xia, X., He, Z., Li, X., Wang, C., Li, Z., et al. (2013). Molecular mapping of leaf rust resistance gene LrNJ97 in Chinese wheat line Neijiang 977671. Theor. Appl. Genet. 126, 2141-2147. doi: 10.1007/s00122-0132124-7

Zou, S., Wang, H., Li, Y., Kong, Z., and Tang, D. (2018). The NB-LRR gene Pm60 confers powdery mildew resistance in wheat. New Phytol. 218, 298-309. doi: $10.1111 /$ nph.14964

Conflict of Interest: The authors declare that the research was conducted in the absence of any commercial or financial relationships that could be construed as a potential conflict of interest.

Copyright (c) 2020 Qiu, Wang, Li, Wang, Liu, Mu, Geng, Guo, Hu, Ma, Sun and Xie. This is an open-access article distributed under the terms of the Creative Commons Attribution License (CC BY). The use, distribution or reproduction in other forums is permitted, provided the original author(s) and the copyright owner(s) are credited and that the original publication in this journal is cited, in accordance with accepted academic practice. No use, distribution or reproduction is permitted which does not comply with these terms. 